\title{
PRODUÇÃO CIENTÍFICA NO CAMPO DAS CIÊNCIAS HUMANAS E SOCIAIS: 0 QUE MUDA COM A RESOLUÇÃO №510/16?
}

\section{Jennifer Galvão Cezar ${ }^{1}$ \\ Maria das Graças Oliveira² \\ Marta Isabel Canese Estigarribia ${ }^{3}$}

Resumo: O objetivo deste trabalho foi apresentar uma discussão sobre as mudanças decorrentes da Resolução $n^{\circ} 510 / 16$ no âmbito da pesquisa científica envolvendo seres humanos. Para tanto, o objetivo específico desta pesquisa foi: comparar as Resoluções $n^{\circ} 466 / 12$ e $n^{\circ} 510 / 16$, apontando os avanços e inovações. Trata-se de um estudo de base bibliográfica realizado a partir de documentos oficiais e artigos pertinentes ao tema. Pela análise realizada, foi possível perceber que a publicação dessa Resolução constitui um marco relevante para a comunidade científica, tendo em vista que somente após vinte anos desde a Res.n¹96/96 é dado às Ciências Humanas e Sociais o reconhecimento de sua especificidade metodológica no fazer científico.

Palavras-chave: Pesquisa Científica; Ciências Humanas e Sociais; Resolução n 510/16.

\footnotetext{
1 Doutoranda em Ciências da Educação/Universidad Columbia, Paraguay. E-mail: jennifer.cezar@yahoo.com.br. 2 Doutoranda em Ciências da Educação/Universidad Columbia, Paraguay. E-mail: grace.olive@gmil.com.

3 Doutora em Ciências da Educação/Universidad Columbia, Paraguay. E-mail: mcanese@gmail.com.
} 